Otterbein University

Digital Commons @ Otterbein

Nursing Student Class Projects (Formerly MSN)

Student Research \& Creative Work

2016

\title{
ARDS: Acute Respiratory Distress Syndrome
}

Jeffrey Lobacz

Otterbein University, jeffrey.lobacz@otterbein.edu

Follow this and additional works at: https://digitalcommons.otterbein.edu/stu_msn

Part of the Nursing Commons

\section{Recommended Citation}

Lobacz, Jeffrey, "ARDS: Acute Respiratory Distress Syndrome" (2016). Nursing Student Class Projects (Formerly MSN). 172.

https://digitalcommons.otterbein.edu/stu_msn/172

This Project is brought to you for free and open access by the Student Research \& Creative Work at Digital Commons @ Otterbein. It has been accepted for inclusion in Nursing Student Class Projects (Formerly MSN) by an authorized administrator of Digital Commons @ Otterbein. For more information, please contact digitalcommons07@otterbein.edu. 


\section{Acute Respiratory Distress Syndrome: ARDS}

Jeffrey Lobacz RN, BSN, CCRN

Otterbein University, Westerville, Ohio

\section{Introduction}

In the 1960 's, military physicians discovered a distinct hypoxic condition involving both
ungs simultaneously (Modrykamien \& Gupta, 2015). In Vietnam, this condition was referred to by physicians as "shock lung". Meanwhile, civilian physicians who encountered this condition termed it adult respiratory distress syndrome. The term was
later modified to acute respiratory distress syndrome (ARDS) after determining that similar later modited toses exised

ARDS develops after insult to the lung tissue. There are many conditions that can
precipitate such an injury. Some of the more common precipitating factors include.

$$
\begin{array}{ll}
\vdots & \text { Sepsis } \\
\vdots & \text { Aspiration } \\
\vdots & \text { Paunconia } \\
& \text { Tracratitis } \\
& \text { Truuma (Hansen-Flaschen \&Siegel, 2016) }
\end{array}
$$

Despite advances in treatment of ARDS, incidence and mortality remain high. In the
United States, ARDS has an estimated incidence of 190,000 cases per year and a mortity rate of 26\% to $58 \%$ (Modrykamien \& Gupta, 2015). In a recent study, ARDS represented 10.4\% of total intensive care unit (ICU) adm 20
mechanical ventilation. (Bellani et al., 2016).

\section{Chest X-ray of ARDS patient Nomal}

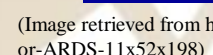

Signs and Symptoms Berlin definition of ARDS, certain criteria must be met, including: an acute onset of hypoxemia
radiographic imaging showing bilateral pulmonary infiltrates
the event is not cardiogenic in nature (Hansen-Flaschen \&Siegel,

The signs and symptoms of ARDS are related to these findings and include

dyspnea
cyanosis

diffuse crackles (Hansen-Flaschen \&Siegel, 2016)
arterial blood gas revealing hypoxemia

- eventual respiratory failure (Hansen-Flaschen \&Siegel, 2016).

In addition to the symptoms related to respiratory distress and subsequent respiratory
failure, ARDS patients will typically display, symptoms of the precipitating disease process
ARDS Pathophysiology

The pathophysiology of ARDS primarily involves an initial lung injury followed by 作 process (Fujishima, 201

\section{Tissue Injury}

Normally, physical barriers including endothelial and epithelial cell layers, the basement membrane, and the extracellular matrix help healthy lungs maintain dry alveoli by
regulating the passage of fluid from the pulmonary capilaries to the alveoli (Fuish

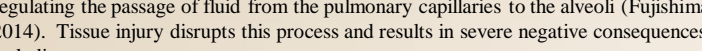

Destruction of the microvascular make-up allows leakage of blood products and proteins from the capillaries to the alveoli (Fujishima, 2014).

With proteins leaking out of the capillaries, the oncotic gradient no longer favors
reabsorption of fluid into the intravascular space (Hansen-Flaschen \& Siegel, 2016) The flood of exudate into the airspace perpetuates tissue injury leading to further
release of pro-inflammatory cytokines (Hansen-Flaschen \& Siegel, 2016).

The Innate Immune System and Inflammation The innate immune system plays a major role in the dysregulation of the inter- and
intracellular molecules that increase vascular permeability and subsequent tissue d particularly the stimultion of alveolar macrophyges and neutrophils Onen tissue damage, macrophages recruit neutrophils and circulating macrophages to the site of injury where hey perpettuate the inflammatory response by promoting the release of biochemical mediators such as, proteases, reactive ox ,
cytokines (Han \& Mallampalli, 2015).

These cytotoxic molecules cause tissue necrosis as well as the induction of distal cell
death, including the destruction of type II epithelial cells. This is of particular importanes since type II epithelial cells are responsible for making surfactant, a substance that lines the alveoli, lowers surface tension and prevents alveolar collapse (Han \& Mallampalli, 2015). Some of the inflammatory cytokines that are shown to be elevated in ARDS recognition receptors (PRRs) and their involvement in the development of ARDS. Particularly the toll-like receptor (TLR) signaling pathway. It's believed that hyaluronan an extracellular matrix of glycosaminoglycan produced after tissue injury, initiates the
inflammatory response in ARDS through TLR2 and TLR4 (Han \& Mallampalli, 2015).
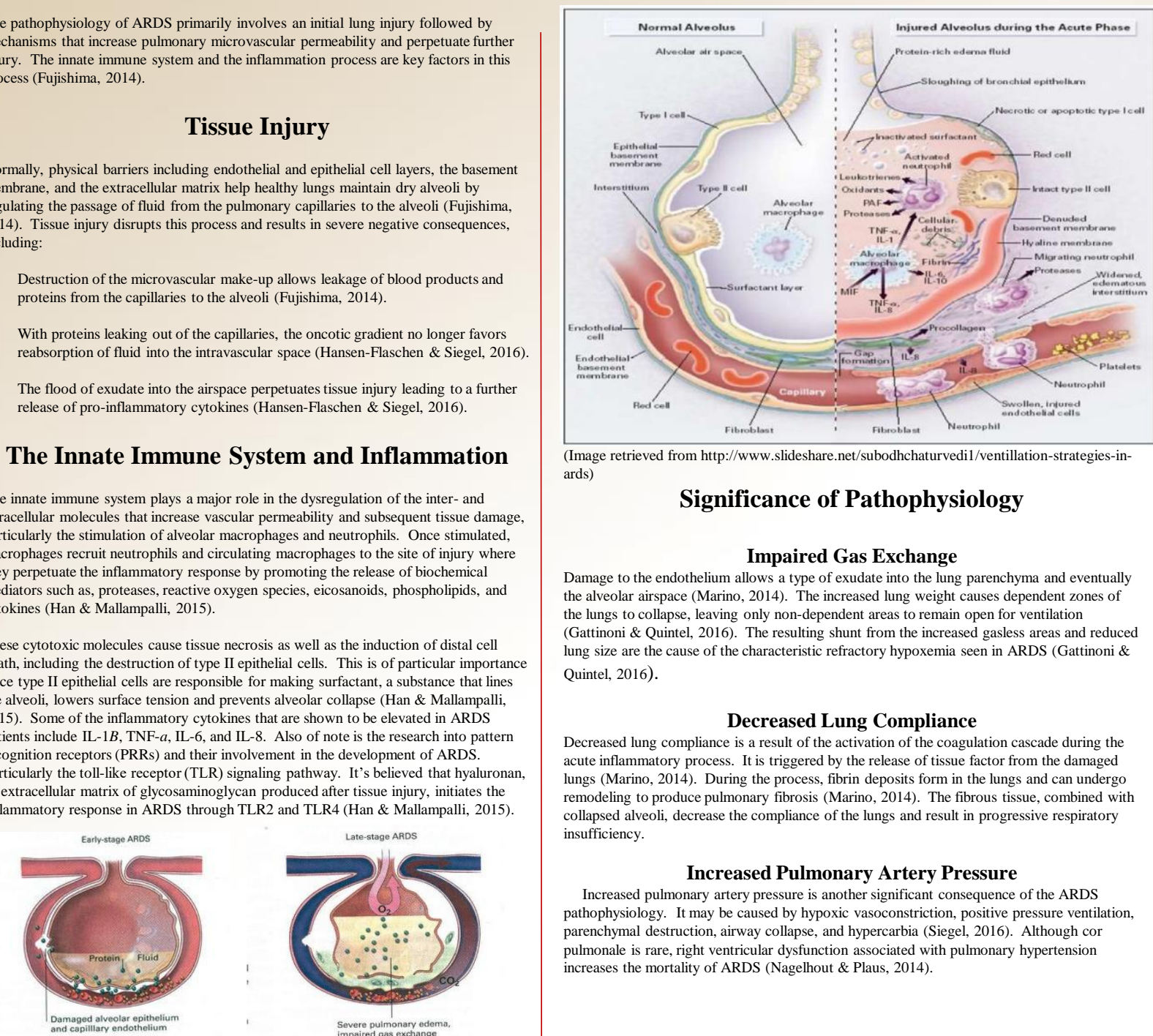
(Image retrieved from http://www.slideshare. net/subodhchaturvedil/ventillation-strategies-in-

Significance of Pathophysiology Impaired Gas Exchange Damage to the endothelium allows a type of exudate into the lung parenchyma and eventually
the alveolar airspace (Marino, 2014). The increased lung weight causes dependent zones of the alveolar airspace (Marino, 2014). The increased lung weight causes dependent zon
the lungs to collapse leaving only non-dependent areas to remain open for ventilation

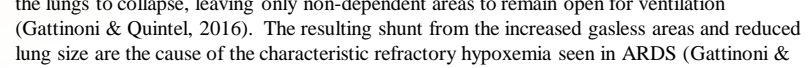
Quintel, 2016).

Decreased Lung Compliance Decreased lung compliance is a result of the activation of the coagulation cascade during the lungs (Marino, 2014). During the process, fibrin deposits form in the lungs and can undergo remodeling to produce pulmonary fibrosis (Marino, 2014). The fibrous tissue, combined with collapsed alve
insufficiency.

Increased Pulmonary Artery Pressure Increased pulmonary artery pressure is another significtant conssquence of the ARDS parenchymal destruction, airway collapse, and hypercarbia (Siegel, 2016). Although cor pulmonale is rare, right ventricular dysfunction associated with pulmonary hypertension increases the mortality of ARDS (Nagelhout \& Plaus, 201

Nursing Implications

These patients are typically going to require
intensive care. It is the duty of the ICU nursing staff to understand the progression treatment, and potential complications of
this disease. The ARDS patient can be incredibly complex, requiring some of the
most advanced therapy and equipment seen in the ICU, including, advanced ventilator management, pronation beds, advanced
hemodynamic monitoring, vasoactive medications, and neuromuscular blocking
agents (Modrykamien \& Gupta, 2015). manage these patients alone. They must be adept in working as part of an with phiciny team, able to collaborate with physicians, respiratory therapists, an
other members of the treatment team to ensure optimal therapy.

Conclusion As of now, the only treatment for ARDS is supportive care aimed at improving gas
exchange. The standard of care is lung protective ventilation strategies including protective ventlation stralegies incla ong
low-tidal volumes and utilization of positive
end expiratory pressure (PEEP). As well end expiratory pressure (PEEP). As we
the use of more aggressive strategies the use of more aggressive strategies
including neuromuscular blockers and
prone positioning Although these therapes prone positioning. Although these therapies
are currently the only treatments shown to are currently the only treatments shown to
improve mortality, efforts are being made to improve mortality, efforts are being made
identify treatments aimed at modulating the
inflammatory response. (19)

It is the responsibility of the nurse, and the
rest of the treatment team, to be aware of the disease process, associated therpy optins As most up to date therapy options. As a aeam, the various
disciplines can utilize their expertise to optimize the patients' ventilation status
while treating the underlying caus. Wit deeper understanding of the pathophysiologic process of ARDS, clinicians can better implement treatrne
plans to improve patient mortality.
References
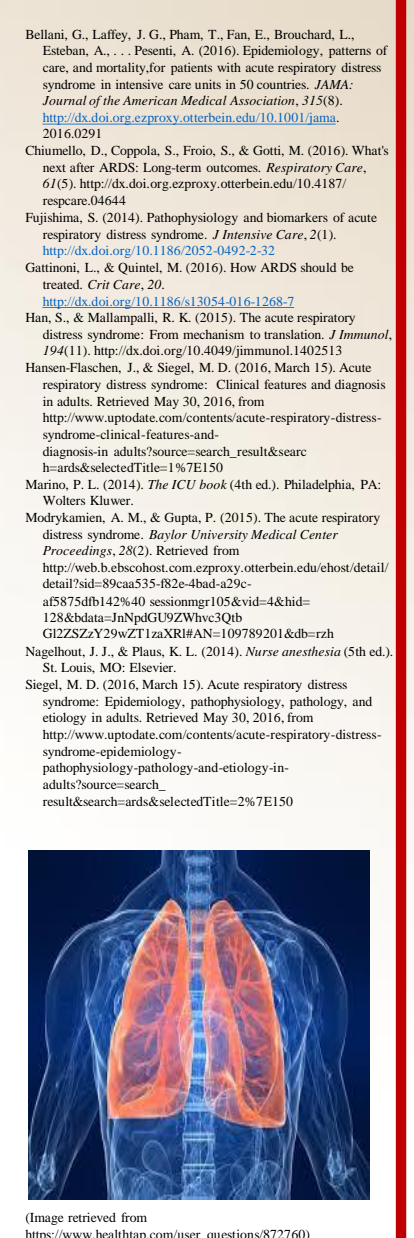

(iii)

OTTERBEIN UNIVERSITY 